Article

\title{
Intercultivar Diversity of Sour Orange (Citrus aurantium L.) Based on Genetic Markers, Phenotypic Characteristics, Aromatic Compounds and Sensorial Analysis
}

\author{
Vincent Ferrer ${ }^{1,2}$, Gilles Costantino ${ }^{1}$, Mathieu Paoli ${ }^{3}$ (D), Noémie Paymal ${ }^{2}$, Carole Quinton ${ }^{2}$, Patrick Ollitrault ${ }^{1,4}$, \\ Félix Tomi ${ }^{3}{ }^{-1}$ and François Luro ${ }^{1, *}$ \\ 1 UMR AGAP Institut, CIRAD, INRAE, Institut Agro, University Montpellier, 20230 San Giuliano, France; \\ vincent.ferrer@inrae.fr (V.F.); gilles.costantino@inrae.fr (G.C.); patrick.ollitrault@cirad.fr (P.O.) \\ 2 Rémy Cointreau —Les Molières, 49124 Saint-Barthélemy-d'Anjou, France; \\ noemie.paymal@remy-cointreau.com (N.P.); carole.quinton@remy-cointreau.com (C.Q.) \\ 3 UMR SPE 6134, Equipe chimie et Biomasse, Université de Corse-CNRS, 20000 Ajaccio, France; \\ paoli_m@univ-corse.fr (M.P.); tomi_f@univ-corse.fr (F.T.) \\ 4 CIRAD, UMR AGAP, F-20230 San Giuliano, France \\ * Correspondence: francois.luro@inrae.fr
}

\section{check for} updates

Citation: Ferrer, V.; Costantino, G.; Paoli, M.; Paymal, N.; Quinton, C.; Ollitrault, P.; Tomi, F.; Luro, F. Intercultivar Diversity of Sour Orange (Citrus aurantium L.) Based on Genetic Markers, Phenotypic Characteristics, Aromatic Compounds and Sensorial Analysis. Agronomy 2021, 11, 1084. https://doi.org/10.3390/agronomy 11061084

Academic Editor: Michela Troggio

Received: 19 April 2021

Accepted: 24 May 2021

Published: 27 May 2021

Publisher's Note: MDPI stays neutral with regard to jurisdictional claims in published maps and institutional affiliations.

Copyright: (c) 2021 by the authors. Licensee MDPI, Basel, Switzerland. This article is an open access article distributed under the terms and conditions of the Creative Commons Attribution (CC BY) license (https:/ / creativecommons.org/licenses/by/ $4.0 /)$.

\begin{abstract}
Sour oranges (Citrus aurantium L.) are well known in the processing and cosmetics industries for the aromatic properties of their essential oils. Intercultivar genetic and aromatic diversity is not well documented. The objective of this study was to evaluate the impact of morphological selection and genetic mechanisms of varietal diversification (mutation or hybridization) on the aromatic and odor variability of sour orange essential oils. Forty-five sour orange accessions from INRAE-CIRAD citrus Biological Resources Center (France) were assessed for ten simple sequence repeat (SSR) and 54 single nucleotide polymorphism (SNP) markers, nine morphochemical fruit traits and with the aromatic components of leaf and peel essential oils. Thirty-nine sour oranges displayed no intercultivar molecular polymorphism and six genotypes originated from interspecific hybridizations involving sour orange, citron, pummelo or mandarin. The peel essential oil (PEO) diversity was low, in accordance with the genetic diversity. The predominance of limonene ( $>90 \%$ ) prevents any possible correlation to be made between the composition and the variation in sensory profiles detected by panelists. Few compounds in the leaf essential oil (LEO), such as linalool, linalyl acetate, $\alpha$-terpineol and geraniol were significantly different across sour oranges varieties. The morphological fruit attributes mainly used in varietal selection differed highly across the main genetically identical group of sour orange accessions. These results confirm that mutation can generate variability in aromatic compounds and aromas and that their exploitation requires an improvement in characterization processes.
\end{abstract}

Keywords: peel and leaf essential oils; GC-MS; SSR; SNP; PCA; citrus color index; acidity

\section{Introduction}

The regular sour orange belongs the Rutaceae family. Its genetic origin is now commonly accepted to be direct hybridization between a pure male mandarin (C. reticulata Blanco) and a pummelo (C. maxima (Burm.) Merr.) [1,2]. Although its precise geographical origin is unknown, it probably originated between the southern China, northern Burma and northeastern India; then, it spread worldwide following traders and discoverers very early in recorded history. Sour orange was probably cultivated in India and China hundreds of years ago, before the Christian era [3]. Sour orange became a major rootstock at the end of the 19th century to fight against Phytophtora gummosis [4]. When used as a rootstock, sour orange also promotes high yield, high quality fruits and tolerance to various stresses, such as root rot, high $\mathrm{pH}$, salinity, flooding, cold and blight. Unfortunately, its popularity has decreased with the emergence of citrus tristeza virus (CTV) [5]. Even if 
regular sour orange is resistant to $\mathrm{CTV}$, if a sensitive scion is grafted onto sour orange and infected with CTV the defense mechanism of sour orange will induce a necrosis at the graft junction and death of the scion [6]. Sour orange fruit is directly cultivated mainly for flavorings, marmalades and perfumes with the whole fruit being used in the case of marmalade, and only the peel, leaf or flower oils in flavorings and perfumes. There are also many minor traditional and medicinal uses [7]. Oil production is estimated to two hundred and twenty tons per year for leaves oil (petitgrain), to one ton per year for flower oil (neroli) and twenty-five to thirty tons/year for PEO [8,9]. This production is characterized by low volumes with high monetary value [10]. Phenotypically Tanaka's classification distinguished numerous sour orange species (C. aurantium L., C. myrtifolia Raf., C. neoaurantium Tan ... ), whereas Swingle and Reece described only one group, C. aurantium [11,12]. Mabberley (1997) extended C. $\times$ aurantium (L.) to other horticultural groups involving C. reticulata and C. maxima in their origins, particularly sweet oranges and grapefruits [13]. Those classification systems for sour orange and the entire Citrus genera are still debated because full sexual compatibility exists between species [14]. Classification is hampered by the high frequency of mutation and the nucellar embryony (apomictic reproduction) that fixes and amplifies the new phenotypes [15]. Recently, a new classification system was proposed based on phylogenomic data and regular sour orange was denoted as follows: C. $\times$ aurantium var. aurantium [16].

Previous studies revealed that the phenotypic diversity within sour oranges is based on fruit, leaf morphology, leaf proteins and also by the pulp sweetness and acidity [17-19]. These studies were carried out on approximately ten to twenty samples including some hybrids, such as Bergamot, which is the product of a cross between a lemon and a sour orange, thus increasing the observed diversity.

Some studies have attempted to asses sour orange genetic diversity. Most studies, mainly using codominant markers such as simple sequence repeat (SSR) markers, concluded that the intervarietal polymorphism was null or very low [20-23]. Only a few sour orange varieties displayed distinct profiles, such as 'Gou Tou', 'Smooth Flat Seville', 'Tosu', 'Konejime', 'Guo-Kuo-Cheng', 'Goutoucheng' and 'Australian' [22,24,25]. Six cultivars of sour orange were compared using NGS DNA sequences from SSR and indel regions of nuclear and organellar genomes. Only a single mutation in a microsatellite was observed in the "Chinotto" cultivar [26].

The aromatic properties and composition of sour orange PEO have been extensively studied and reviewed. The composition is dominated by hydrocarbon monoterpenes, low amounts of aliphatics and several sesquiterpenes [27-30]. The aromatic properties of sour orange LEO have been less studied than those of PEO. LEO is mainly composed of oxygenated monoterpenes with lower amounts of hydrocarbon monoterpenes and a few sesquiterpenes [29,30]. Many factors can modify the sour orange PEO composition, such as cultivars (genetic variability), geographic origins, fruit development stages, storage conditions and extraction methods [31]. The results of all studies agreed with the very low chemical variability detected among sour orange cultivars $[8,17]$. The influence of four different growing locations (Brazil, Tunisia, Corsica and Greece) on the compositions of $\mathrm{PEO}$, leaf and flower oils was low [32]. Seasonal variation was detected in the composition of petit grain and significantly modified the proportions of the main monoterpenes $[33,34]$.

The aromatic profile of PEO analyzed by gas chromatography-olfactometry (GC-O) was supported by nine oxygenated compounds characteristic of sour orange as demonstrated by model reconstruction methods [35]. Nineteen compounds were identified with major odor activity, most of which were oxygenated compounds or major compounds [36].

The objective of this study was to evaluate the effects of genetic diversification patterns within sour orange trees on the phenotypic diversity of the fruit, on the biochemical diversity of the aromatic compounds, and on the aromatic sensory diversity. Genetic markers specific to the four ancestral citrus species were used to define the origin of a few hybrid varieties classified as sour oranges. 


\section{Materials and Methods}

\subsection{Biological Materials}

All the biological materials used in this study came from the orchard of the INRAECIRAD citrus collection at San Giuliano, France (latitude $42^{\circ} 17^{\prime} \mathrm{N}$, longitude $9^{\circ} 32^{\prime} \mathrm{E}$; Mediterranean climate, average rainfall of $840 \mathrm{~mm}$ per year and average temperature of $15.2{ }^{\circ} \mathrm{C}$; soil derived from alluvial deposits and classified as fersiallitic, with a $\mathrm{pH}$ range of 5.0-5.6) [37]. Forty-five sour orange accessions grafted on the same rootstock (Carrizo citrange, [C. sinensis $\times$ Poncirus trifoliata]) and grown under identical conditions were used for the analysis of phenotypic and aromatic diversity. For the genetic analysis, one additional variety of each of the four ancestral species was included as a reference to help us determine the genetic origin of sour orange accessions (Table S1).

\subsection{Phenotypic Description}

\subsubsection{Data Acquisition}

To perform the phenotypic analysis five representative fruits from three different trees each of forty-three accessions ("Bizzaria" and "A fleurs grosses Carle" were not phenotyped) of sour orange were harvested during the first week of March 2019 corresponding to fully ripened fruits. In this study all the fruits were individually measured.

The polar and equatorial diameters (PD and ED) of each fruit were measured using a caliper model IP 67 (BLET, Rueil-Malmaison, France), and their ratio (PD/ED) yields the shape of the fruits: flattened for values below 1 and oblong for values higher than 1. The weight $(\mathrm{W})$ of each fruit was measured using a balance model PIONNER (OHAUS, Parsippany, NJ, USA). The thickness of the peel (PT) was measured using a caliper IP 67 model (BLET, Rueil-Malmaison, France). The number of segments (NS) of each fruit were individually counted. The color of the flavedo fruit peel was measured using a colorimeter model Chroma meter CR-400 (Konica Minolta Sensing, Ramsey, NJ, USA) with the determination of $\mathrm{a}^{*}, \mathrm{~b}^{*}$, and $\mathrm{L}$ color indices, where $\mathrm{a}^{*}$ corresponds to the variation between green and red, $b^{*}$ corresponds to the variation between blue and yellow, $\mathrm{L}$ is the brightness variation between black and white, the combination of these variables permit to calculate the Citrus Color Index (CCI). These variables were then applied in the formula $\mathrm{CCI}=1000 \times \mathrm{a}^{*} /\left(\mathrm{L} \times \mathrm{b}^{*}\right)$, with variation between -20 (green) and +20 (orange), where zero (0) corresponded to yellow [38]. Each fruit was measured four times around the equatorial line.

Five fruits from each tree were separately hand-pressed and equal proportions were mixed in three lots per cultivar to perform the following juice analysis. The total soluble solid (TSS) content expressed in Brix was measured three times using an RFM710 refractometer (Bellingham + Stanley ${ }^{\circledR}$, Weilheim in Oberbayern, Germany). The acidity (AC) expressed in percent (gram of citric acid per $100 \mathrm{~g}$ of juice) was measured three times using an 855 Robotic Titrosampler, $\left(\Omega\right.$ Metrohm $^{\circledR}$, Herisau, Switzerland).

The fruit base and the cross-section of the eight most representative cultivar in terms of diversity were photographed and graded based on the same scale.

\subsubsection{Statistical Analysis}

The distribution of each parameter (W, CCI, NS, PT, TSS, AC and PDED) was represented using a violin plot coupled with a boxplot using the $\mathrm{R}$ (v4.0.1) package ggplot2 [39]. Significant differences within cultivars were calculated for each parameter using one-way analysis of variance (ANOVA) and Tukey's test using the agricolae package in R [40].

To decipher the structure of our cultivars based on all the phenotypic parameters, we performed principal component analysis (PCA) using the following packages in R: ade4, FactoMineR and factoextra [41-43]. 


\subsection{Essential Oil Analysis}

\subsubsection{Raw Materials}

To perform the PEO extraction the fruits were harvested in January 2019 and handpeeled in order to obtain approximately $250 \mathrm{~g}$ of fresh material for the forty-four sour orange accessions. The fruits were picked randomly from three different trees.

The LEO extraction was conducted with $100 \mathrm{~g}$ of leaves at their maximum development point that were harvested in June 2019 from three different trees of the fourty-four cultivars (except "Bizzaria").

A second LEO extraction was conducted one year later (June 2020) on three different trees for each of six cultivars to confirm the reproducibility of the previous leaf analysis and to asses cultivar variability. The six cultivars were chosen because they were representative of the range of chemical diversity found in the first LEO experiment.

\subsubsection{Hydro Distillation}

Hydrodistillation, $250 \mathrm{~g}$ of fruit peel material was blended with distilled water oneminute using a blender model 1300W (Magimix, Vincennes, France). The leaf materiel was not blended.

The samples were reacted in a $2 \mathrm{~L}$ wide neck flask with a final volume of one liter (sample and distilled water) and heated for two and a half hours using a heating mantle model EM2000/CE (Eletrothermal ${ }^{\circledR}$, London, England) thermostat 7. The essential oil was collected using a classical Clevenger apparatus. The Clevenger apparatus was cooled using a refrigerated fluid (mix of glycol/water) cooled at $4{ }^{\circ} \mathrm{C}$ and moved by a minichiller model C20 (Huber ${ }^{\circledR}$, Offenburg, Germany).

Then the essential oils were stored in overfull $300 \mu \mathrm{L}$ tainted vial and stored at $-20{ }^{\circ} \mathrm{C}$ before further analysis.

2.3.3. Essential Oil Analysis Using Gas Chromatography and Gas Chomatrography-Mass Spectrometry

Gas chromatography analyses were performed on a Clarus 500 gas chromatograph (PerkinElmer, Waltham, MA, USA) equipped with flame ionization detector and equipped with two fused silica gel capillary columns $(50 \mathrm{~m}, 22 \mathrm{~mm}$ id, film thickness $0.25 \mu \mathrm{m}$ ), BP-1 (polydimethylsiloxane) and BP-20 (polyethylene glycol). The oven temperature was programmed from 60 to $220{ }^{\circ} \mathrm{C}$ at $2{ }^{\circ} \mathrm{C} / \mathrm{min}$ and then held isothermal at $220{ }^{\circ} \mathrm{C}$ for $20 \mathrm{~min}$, with injector temperature $250{ }^{\circ} \mathrm{C}$, detector temperature $250{ }^{\circ} \mathrm{C}$, carrier gas hydrogen $(1.0 \mathrm{~mL} / \mathrm{min})$, and split $1 / 60$. The relative proportions of the oils constituents were expressed as percentages obtained by peak area normalization, without using correcting factors. Retention indices were determined relatives to the retention times of a series of n-alkanes (C7-C28) with linear interpolation ("Target Compounds" software of Perkin Elmer).

Gas chromatography coupled with mass spectrometry were conducted with a TurboMass quadrupole detector (Perkin Elmer, Waltham, MA, USA, directly coupled to an Autosystem XL (Perkin Elmer), equipped with a fused silica gel capillary column (50 m, $0.22 \mathrm{~mm}$ id, film thickness $0.25 \mu \mathrm{m}$ ), (BP-1 polydimethylsiloxane). Carrier gas, helium at $0.8 \mathrm{~mL} / \mathrm{min}$; split $1 / 75$; injection volume $0.5 \mu \mathrm{L}$; injector temperature, $250^{\circ} \mathrm{C}$; energy ionization, $70 \mathrm{eV}$; electron ionization mass spectra were acquired over the mass range $40-400 \mathrm{Da}$. The identification of components was based: on comparison of their gas chromatography retention indices on polar and apolar columns, determined relative to the retention times of a series of n-alkanes with linear interpolation with those of authentic compounds and literature data; on computer matching against National Institute of Standards and Technology (NIST) commercial mass spectral library and by comparison of spectra with literature data. For further information were refer to the publication by Luro et al. [23]. 


\subsubsection{Statistical Analysis}

The structure of all the LEO cultivars was graphically represented using a heatmap. The analysis was performed using the package gplots in R [44]. The LEO diversity of six cultivars with three biological repetition was graphically represented using a cluster dendrogram with the hierarchical clustering method. The analysis was performed in $\mathrm{R}$ using the packages ggplot2, ade4, FactoMineR and factoextra [39,41-43]. ANOVA followed by Tukey's test was conducted on the ten main compounds of the LEO to statistically assess of the observed variability using the agricolae package in R [40].

\subsection{Sensorial Analysis of Sour Orange Peel Oil}

\subsubsection{Tests, Panelists and Descriptors}

Sensorial analysis was performed on the PEO of thirty-nine regular sour oranges (genotypically identical varieties). A check all that apply (CATA) questionnaire was used. Twenty-nine descriptors were selected during consensus training sessions of the Cointreau Expert panel, on a few randomly selected samples of bitter orange essential oils. These descriptors are terms that the Expert panel already uses for Cointreau distillates already identified during CG-O sessions on the distillate (Table S2). The panelists (ten women and eight men aged between 22 and 55) are people from the laboratory who control the quality of the liquids during the manufacturing process and participate in daily tastings.

The pure distilled PEO sample was presented in tainted vials to the panelists. Each PEO sample was identified by a code making it unidentifiable by panelists and given in a random order without prior information. The panelist had one minute to smell the sample using a test strip and tick the perceived aromatic characteristics in the provided chart. The question asked to the panelists is the following: Which of the twenty-nine descriptors characterize the aroma of the sample? Five distinct sessions were conducted for the analysis of the thirty-nine samples.

\subsubsection{Statistical Analysis}

The data from each judge and each session were gathered and transformed into a unique matrix with attributes coded as (1) detected by a panelist and (0) not detected by the panelist for each descriptor, panelist and cultivar. The previous matrix was transformed into a contingency table for further analysis.

Cochran's Q-test $(p \leq 0.05)$ was applied to the raw binary matrix using the RVAideMemoire package in $\mathrm{R}$ to determine significant differences among cultivars for each sensory attribute (Table S2) [45].

Factorial correspondence analysis (FCA) was performed on the contingency table (with only the seven attributes that were significantly different between cultivars according to Cochran's Q-test) using R (v4.0.1) software to detect clustering and to establish relationships between cultivars and sensory attributes. Pearson's chi squared test $(p \leq 0.05)$ was performed on the contingency table (with only the seven attributes that were significantly different between cultivars according to Cochran's Q-test) using R software to determine the existence of a statistical relationship between sensory attributes and cultivars.

\subsection{Genetic Diversity Analysis}

\subsubsection{DNA Extraction}

DNA was extracted from $50 \mathrm{mg}$ of leaves of the forty-five sour orange cultivars using a DNeasy ${ }^{\circledR}$ Plant Mini kit (Qiagen, Hilden, Germany) following the manufacturer's protocol. The DNA quality and concentration were controlled twice using a Nanodrop 2000 spectrophotometer (ThermoFischer Scientific, Waltham, MA, USA) and by electrophoresis on an agarose gel. In total forty-nine DNA samples were extracted from forty-five accessions of sour orange and four other accessions representing the ancestors of commonly cultivated Citrus species including: Poncire commum citron (C. medica), Cleopatra mandarin (C. reticulata), Chandler pummelo (C. maxima) and micrantha (C. micrantha). 


\subsubsection{SSR Genotyping}

Polymerase chain reaction (PCR) was performed in $20 \mu \mathrm{L}$ reaction containing $8 \mathrm{ng}$ of DNA, $0.2 \mu \mathrm{M}$ of each primer, DreamTaq ${ }^{\mathrm{TM}}$ Hot Start PCR Master Mix (ThermoFisher Scientific Waltham, MA, USA) containing Taq polymerase and all other reagents. PCR amplification was performed in a Primus 96+ thermocycler (MWG-Biotech ${ }^{\circledR}$, Luxembourg, Luxembourg), and amplicons were analyzed as described by Luro et al., with the ten pairs of primers (Table S3) [46].

The genetic structure of sour oranges based on allelic data was studied by principal component analysis (PCA) on allelic data using the factoextra package in R [43]. The PCA coordinates of the first three axes of all individuals were plotted on a 3D scatterplot using the package scatterplot3d in R [47].

\subsubsection{SNP Genotyping}

Fifty-four SNP markers were used and included eighteen SNP markers (two per chromosome) for detecting specific alleles for each ancestral species (Table S4). Genotyping was performed with the KasPar competitive, allele-specific dual Förster resonance energy transfer (FRET) — based assay according to the method described by Curk et al. [48]. The three ancestral species used as positive controls were C. maxima, C. reticulata and C. medica. For each cultivar, the total percentage of ancestral alleles was calculated based on raw KasPar data and plotted on a stacked bar graph using the package ggplot2 in R [38].

For each cultivar, the heterozygous and homozygous allele frequencies of the three basic taxa were plotted on a split bar chart.

\section{Results}

\subsection{Genetic Diversity}

A main group composed of thirty-nine cultivars showed no genetic variability based on the ten SSR markers data (Table S3); these cultivars, represented the core group of sour oranges and were positioned close to the representative varieties of mandarin and pummelo on the first two PCA axes (Figure 1). Six distinct genotypes with variable genetic distances from the main group emerged from the analysis. The "Fraser Seville" and "Australian" cultivars displayed relationships with pummelo and mandarin and were probably closer to mandarin as shown by the third axis. They differed slightly from each other by only one marker (MEST375), and they had no alleles in common with regular sour oranges for two markers (TAA41, MEST469). The "Gou Tou" and "Tosu" cultivars had the same genetic profile for three markers (MEST15, MEST88 and MEST488) and had no alleles in common with regular sour oranges. These two cultivars appeared to be less related to the representative varieties of mandarin and pummelo than to the regular sour orange group and were differentiated by the second axis. Finally, "Chinensis" and "Chinensis de semis" were the most distant genotypes from the sour orange main group and both were related to "Poncire commun" citron.

By using diagnostic SNP markers that can differentiate the ancestral species at each studied locus, four genotypes were observed among the sour orange set (Figure 2a and Table S4 for data for each marker). In addition, the frequency of diagnostic alleles with homozygosity and heterozygosity allowed the identification of potential parents (Figure $2 b$ ).

The genome of the thirty-nine regular sour oranges previously characterized by the same SSR markers was composed of $41.7 \%$ C. maxima, $47.2 \%$ C. reticulata and $11.1 \%$ citrus of unknown origin. The frequencies of heterozygous markers for $C$. reticulata and C. maxima were high at 0.96 and 0.61 respectively, suggesting a direct hybrid origin between mandarin and pummelo. 


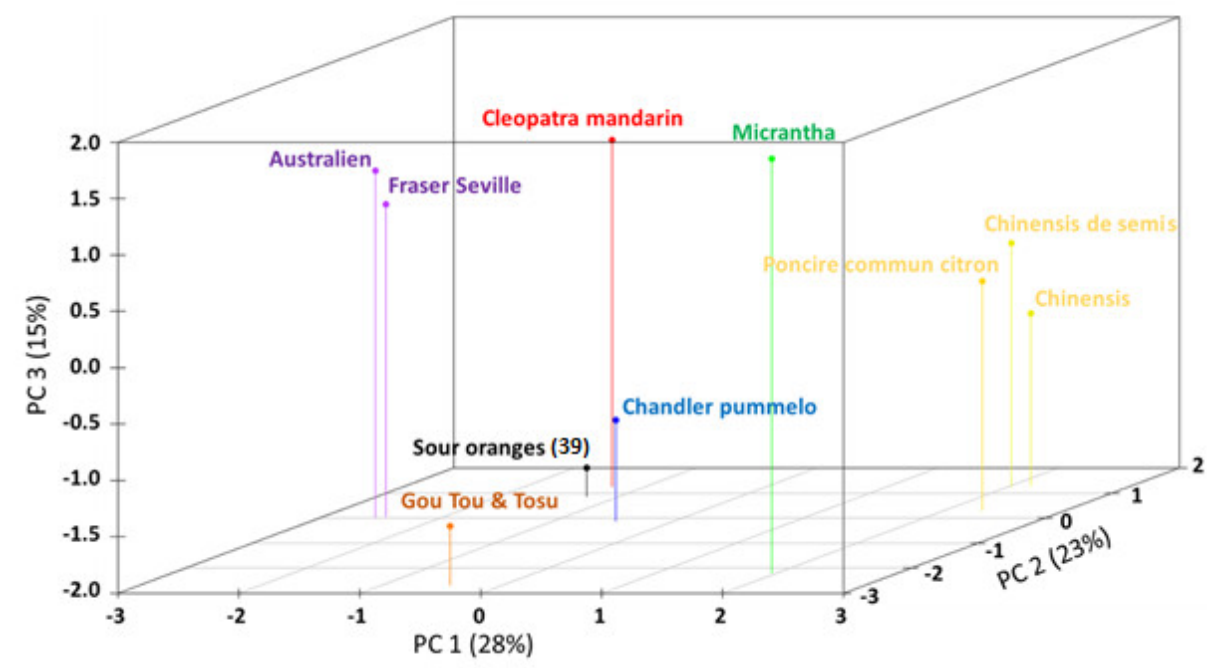

Figure 1. 3D scatterplot of the principal component analysis (PCA) coordinate representing the polymorphism of ten SSR markers.

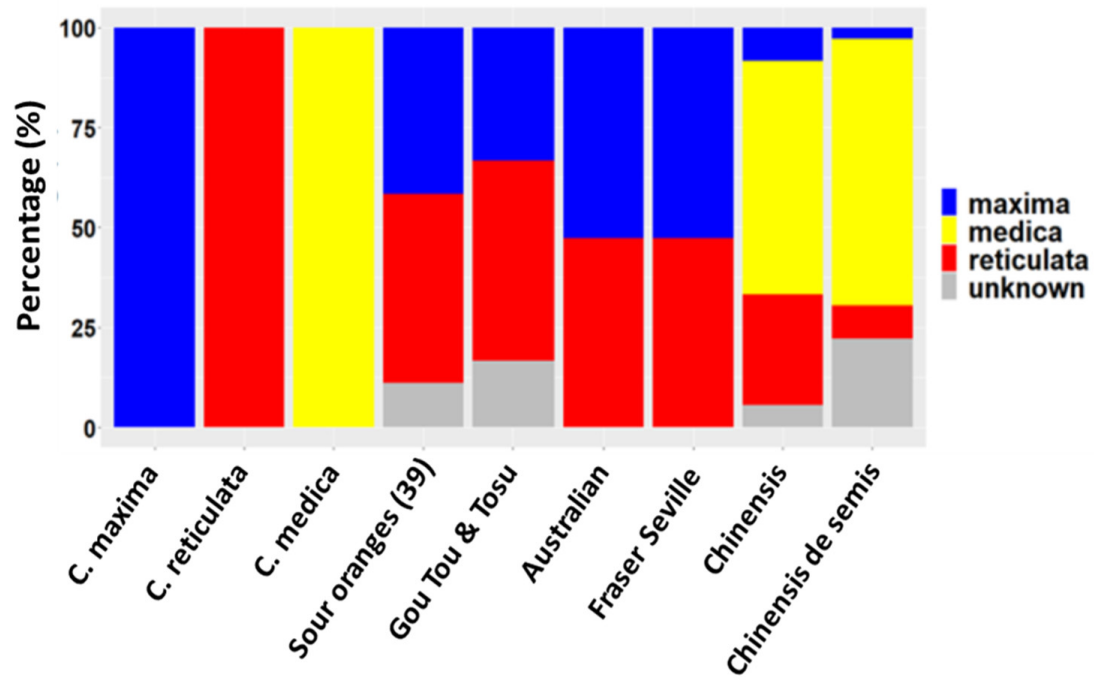

(a)

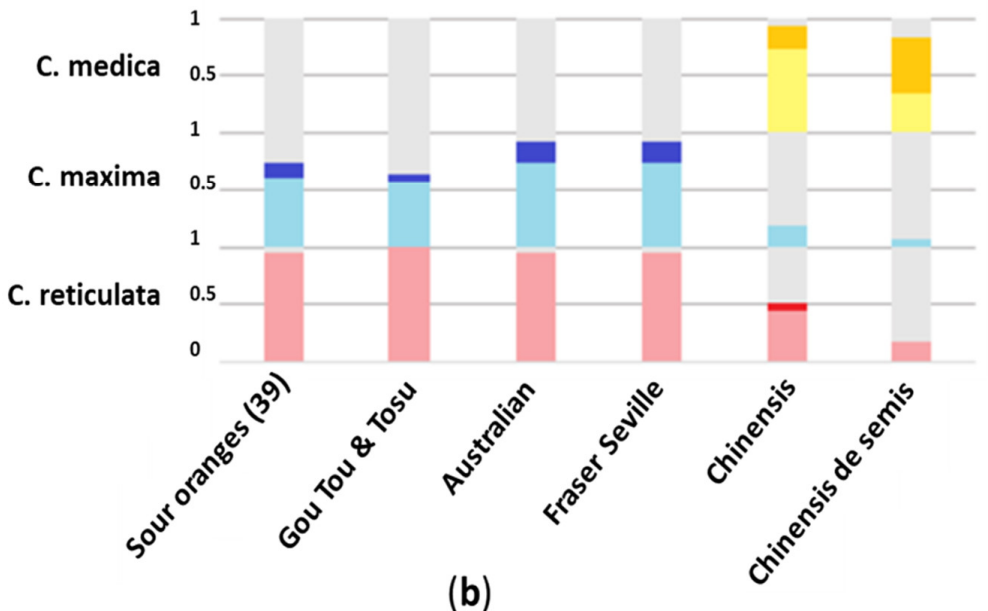

Figure 2. (a) Stacked bar graph representing the proportion of ancestral species genomes of the different sour orange genotypes; (b) Frequency of homozygous and heterozygous SNP alleles of the three basic taxa. Dark color for homozygous alleles, and light color for heterozygous alleles; red for C. reticulata; blue for C. maxima and yellow for C. medica. 
"Australian" (or "Smooth Flat Seville") and "Fraser Seville" had the same constitution, with equal proportions of C. maxima and C. reticulata alleles (52.8 and 47.2\%, respectively). The frequencies heterozygous markers for of C. reticulata and C. maxima were high at 0.94 and 0.72 , respectively, suggesting that those two cultivars were most likely direct hybrids between mandarin and pummelo.

"Gou Tou" and "Tosu" also presented an identical genotype characterized by 33.3\% C. maxima, $50.0 \%$ C. reticulata and $16.7 \%$ citrus of unknown origin. This repartitioning of the allelic parentage differed from the phylogenomic profile of the regular sour orange due to the lower proportion of C. maxima and the higher proportion of alleles of unknown origin. The frequencies of heterozygous markers C. reticulata and C. maxima were high (1 and 0.56, respectively), suggesting a direct hybrid origin between mandarin and pummelo.

The proportions of ancestral species alleles in the "Chinensis" (8.3\% C. maxima, 27.8\% C. reticulate and $58.3 \%$ C. medica) and "Chinensis de semis" (2.8\% C. maxima, 8.3\% C. reticulate and $66.67 \%$ C. medica) genotypes clearly identified citron as one of the parents of those cultivars. The second parent remains unidentified. The homozygous and heterozygous markers frequencies were $0.22 / 0.72$ and $0.50 / 0.33$ respectively, suggesting more than one fecundation event with citron or possibly one fecundation followed by self-fecundation. Pummelo markers were found only in heterozygous state in both cultivars with frequencies of 0.17 and 0.06 for "Chinensis" and "Chinensis de semis", respectively. The frequency of heterozygous mandarin markers were higher for "Chinensis" (0.44) and lower for "Chinensis de semis" (0.17). Interestingly "Chinensis" had a homozygous mandarin markers frequency of 0.06 , whereas "Chinensis de semis" had no homozygous markers.

In conclusion, and for the rest of the study, the thirty-nine cultivars with an identical profile were considered $C$. $\times$ aurantium var. aurantium according to the new phylogenomic classification of regular sour oranges [16].

\subsection{Phenotypic Description of the Fruit}

The phenotypes of the fruits were highly variable between cultivars in terms of size, pericarp color, aspect and internal structure (Figure 3). This diversity in appearance was characterized by the measurements of five morphological characters, one skin character and two chemical attributes of juice (Figure 4 and Table S5). Most of the time the observable phenotypic diversity was in accordance with the genotypic origin. However, the regular sour orange group displayed important phenotypic diversity despite its lack of genetic diversity.

The thirty-seven regular sour orange cultivars ("Bizzaria" and "A fleurs grosses Carle" were removed from the initial set due to a lack of fruits) visually displayed an important phenotypic diversity in terms of size, color and shape. The weight (W) varied between 23 and $260 \mathrm{~g}$. "Chinotto" had the lowest weight and "Bouquetier" had the highest weight. The citrus color index (CCI) varied between 2.2 and 13.4, with a mean value of 8.7 , corresponding to a reddish orange color. The cultivar "Variegated" produced a yellow fruit with orange stripes (Figure 3). The two autotetraploid cultivars "N¹0_4X_SG" and "N'11_4X_SG" presented an altered phenotype with the highest CCI values (13.37 and 12.22). The mean number of segments (NS) varied between 6.8 and 18.2. The distribution was not homogenous because the three outgroups corresponded to "Bouquetier" cultivars, which significantly differed from the others, which had almost twice the number of endocarp sections. The mean peel thickness (PT) varied between "Chinotto" $(2.7 \mathrm{~mm})$ and the tetraploid "N¹0_4X_SG" (10.5 mm). The mean shape value corresponding to the ratio $\mathrm{PD} / \mathrm{ED}$ (polar diameter/equatorial diameter) varied between flattened fruits (0.63-0.80) and round fruits (close to 1). The distribution was homogenous around the median except for the "Bouquetier" cultivars, which were significantly more flattened than the others. The total soluble solids content (TSS) varied between 6.8 and $10.7^{\circ}$ Brix, and the acidity (AC) varied between 0.1 and $4.6 \%$, with a mean value of $2.3 \%$. Low acidity levels $(<0.1 \%)$ characterized "Small leaves Chinotto", "Sweet", "Curacao", "Alibert hyb 12" and "Bitter sweet". The TSS was the character with the largest variation or dispersed distribution 
among the currently observed characteristics. In contrast to TSS and other characteristics, acidity had a normal distribution, with $50 \%$ of the cultivars close to the mean value. The other characteristics demonstrated heterogeneous distributions.

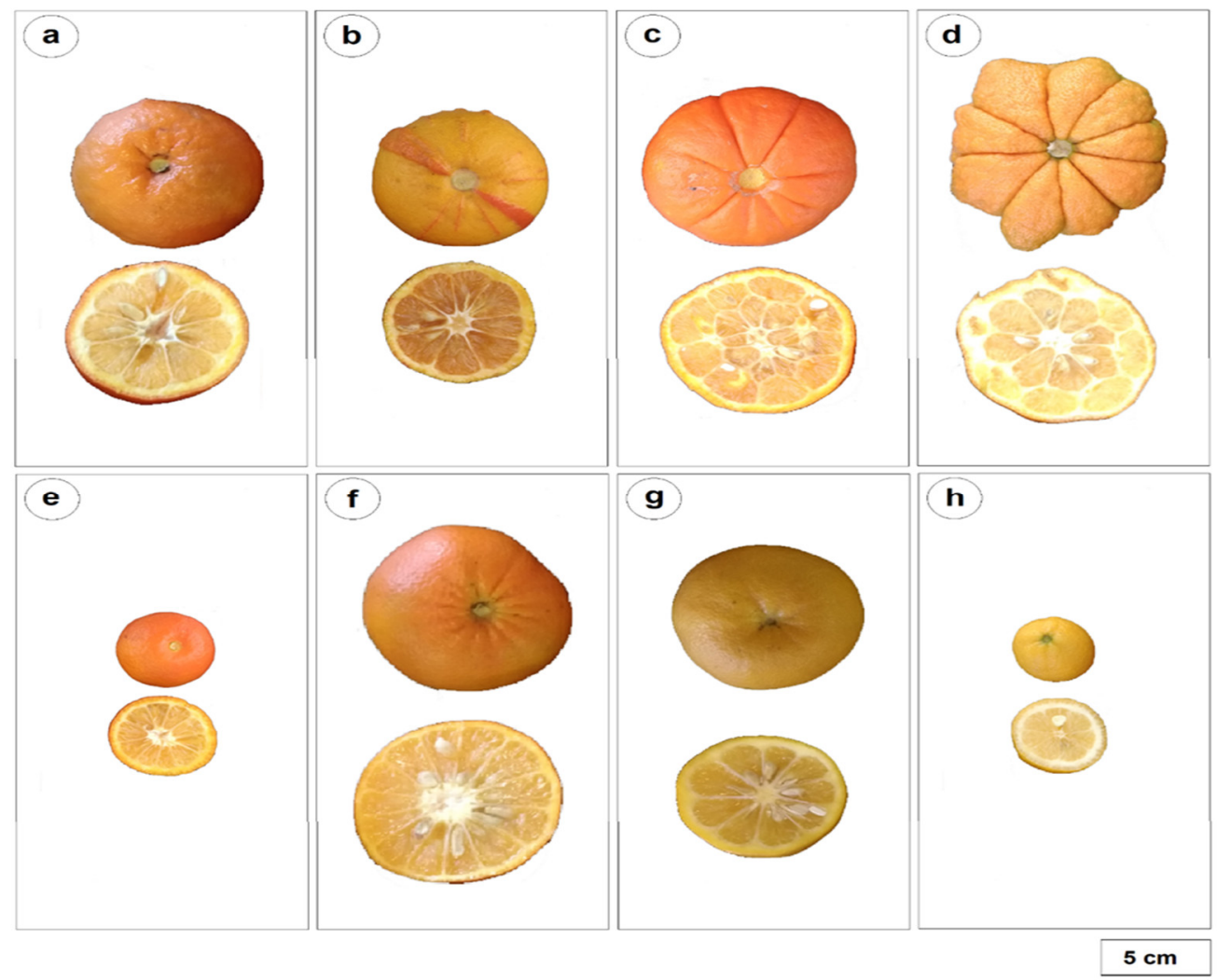

Figure 3. Fruit photography of eight sour orange cultivars illustrating the phenotypic diversity. (a) "Brazil sour", (b) "Variegated", (c) "Bouquetier à fruit plat", (d) "Bouquetier de Nice" this one is a horned cultivar, (e) "Small leaves Chinotto", (f) "Australian" (also named "Smooth flat Seville"), (g) "Gou Tou" and (h) "Chinensis de semis".

The comparative variation of the two juice characteristics (acidity and sugar content) presents a scattered point cloud of varietal diversity, i.e., a representation of numerous combinations of phenotypic profiles (Figure 5). The varietal diversity of the sour oranges was segmented into five chemotypes including four groups and one single variety (Figure 4). Group I included six varieties with low acidity $(<1 \%)$; group II included eight varieties with intermediate acidity $(2.2-3.5 \%)$ and high TSS $\left(>9.5^{\circ}\right.$ Brix). Group III included varieties with intermediate acidity (1.5-3.5\%) but with low TSS ( $<9{ }^{\circ}$ Brix); and group IV included six varieties, including three sour oranges with a unique genetic profile and three hybrids with very high acidity $(>4 \%)$ and TSS $\left(>8.5^{\circ} \mathrm{Brix}\right)$. "Chinensis" is the only variety with very high acidity $(>4 \%)$ and low TSS $\left(<7^{\circ}\right.$ Brix). The dispersion of this diversity suggests an independence of these two traits. 


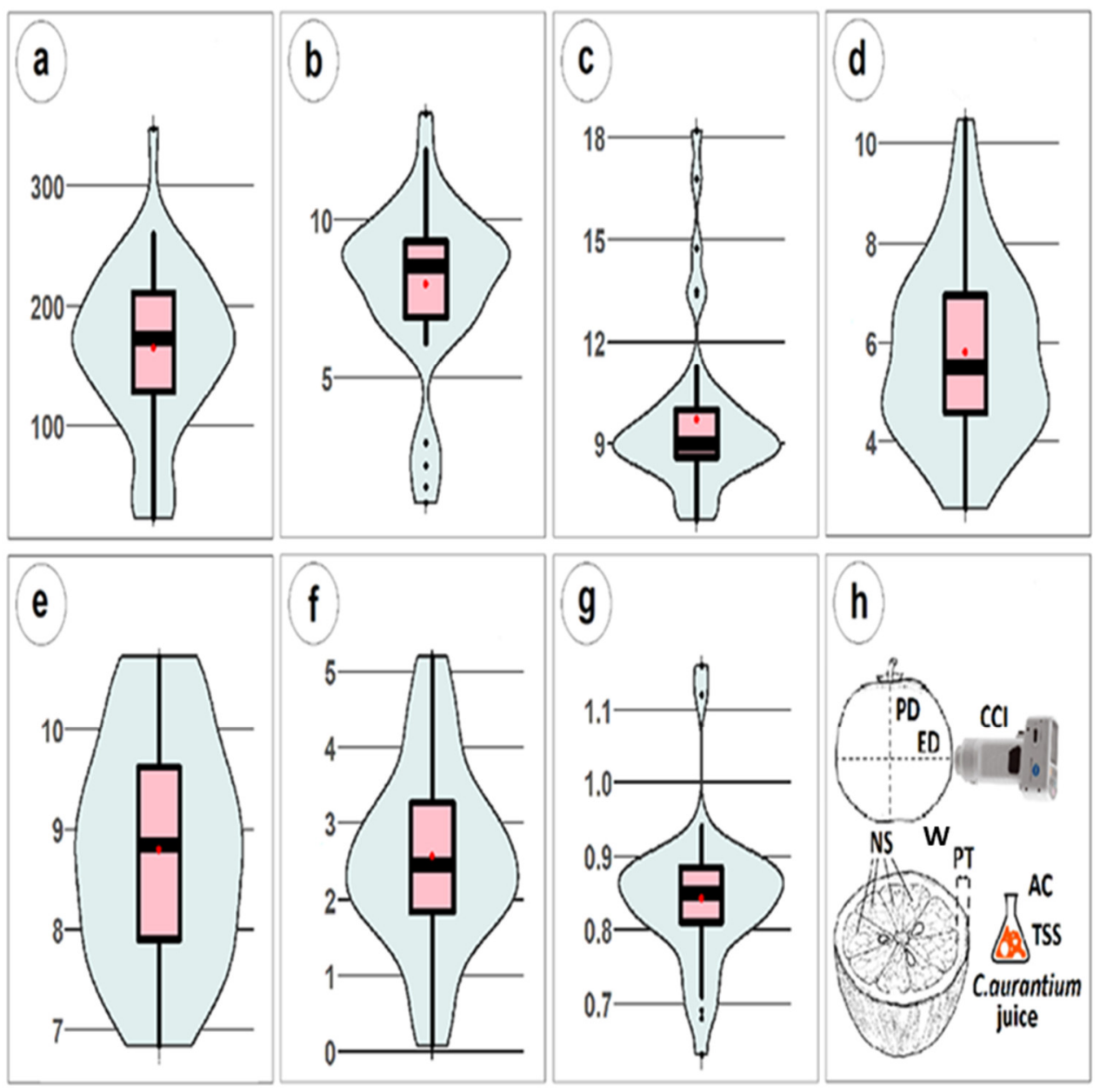

Figure 4. Distribution of phenotype parameters; the red dot represents the mean value of each parameter. (a) Mean weight (W) in grams, (b) mean citrus color index (CCI), (c) mean number of segments (NS), (d) mean peel thickness (PT) in mm, (e) mean total soluble solids (TSS) in ${ }^{\circ}$ Brix, (f) mean acidity $(\mathrm{AC})$ in \%, (g) mean shape corresponding to the PD/ED ratio and (h) summary.

"Gou Tou" and "Tosu" were extremely similar to most regular sour oranges in many aspects (W, NS, PT, TSS and PD/ED) but differed significantly due to its yellowish flavedo and higher juice acidity (AC). "Australian" and "Fraser Seville" were similar with to regular sour orange in PT, CCI and AC characteristics but had larger fruits (W), a higher number of segments (NS), a slightly more flattened shape (PD/ED) and a relatively higher TSS content. "Chinensis" and "Chinensis de semis" were extremely different from the regular sour oranges. Indeed, the fruit were significantly smaller, ellipsoid, and more acidic with a bright yellow flavedo. There are characteristics that were not measured in this study, that are common between these two cultivars and the "Chinotto" type, such as a dwarf of tree shape, the small size and shape of the leaves (myrtle aspect), and the small distance separating leaves on the branch.

The first two axes of the multivariate analysis represented $57 \%$ of the overall diversity, suggesting an average level of structure (Figure 6). 


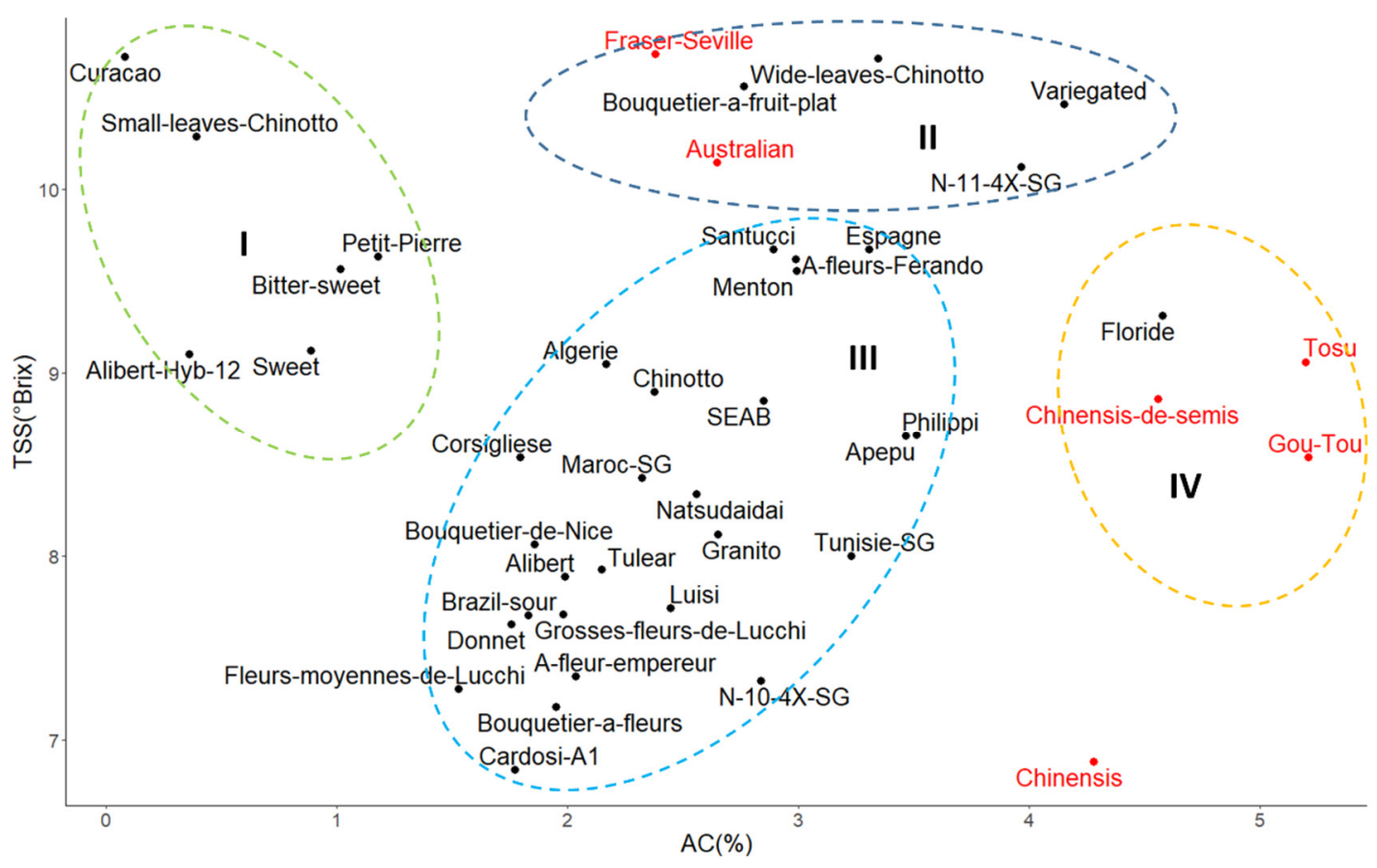

Figure 5. Scatter plot of varietal sour orange diversity based on the sweetness (TSS) and acidity of fruit pulp (AC). Dotted circles and Roman numbers (I to IV) identify the four clusters of phenotypic profiles, the regular sour orange shown in black, and hybrids and outgroups shown in red.

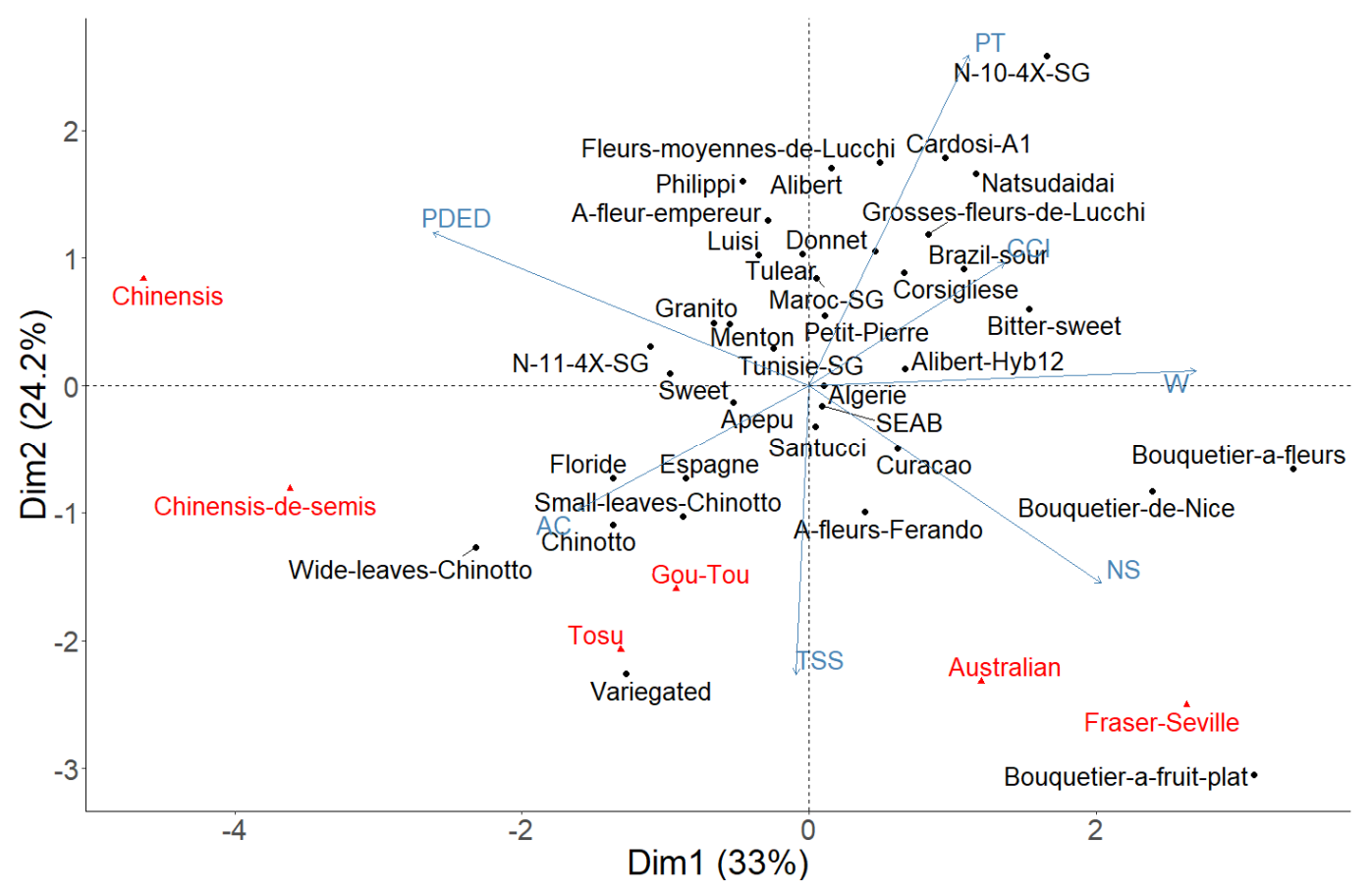

Figure 6. PCA based on seven phenotypic (W, CCI, NS, PT, TSS, AC, PD/ED) shown in blue, the regular sour orange shown in black, and hybrids and outgroups shown in red.

Weight, skin thickness and fruit shape are the main characteristics determining this diversity. The related bitter orange cultivars (different from the basic genetic profile), had several phenotypic aspects that, also differed from those of the regular cultivars. However, some regular varieties also stand out from the lot such as "Bouquetier" (by mass and 
number of segments), "Chinotto" and "Variegated" (by TSS, AC and weight) and the tetraploid variety "No10_4X_SG" (essentially by its peel thickness).

\subsection{Essential Oil Analysis}

\subsubsection{Peel Essential Oil}

Sixty-five compounds were identified in the 45 accessions accounting for 99.96 to $100 \%$ of the total oil composition (Table S6). The PEO of the thirty-nine regular sour oranges was almost exclusively composed of terpenes varying between 98.91 and $99.95 \%$. Limonene was the dominant compound accounting for 89.77 to $95.39 \%$, followed by four compounds at approximately $1 \%$ : myrcene (1.41-1.85\%), $\beta$-pinene (0.21-1.52\%), linalool $(0.21-2.93 \%)$ and $\alpha$-pinene $(0.43-0.65 \%)$. All the remaining compounds represented significantly less than a percent. In this study, we identified eleven nonterpenoids compounds, comprising six aliphatic aldehydes (hexanal, hex-2-enal, octanal, nonanal, decanal and (E)-dodec-2-enal), representing 0.05 to $0.23 \%$ together. Three aliphatic alcohols (hexan-1-ol, nonan-1-ol and decan-1-ol) accounted for traces of $0.05 \%$, and two aliphatic esters (octyl acetate and decyl acetate) accounted for traces of $0.14 \%$. Finally, the proportion of oxygenated compounds varied between 1.00 and $7.14 \%$. The overall chemical diversity of this group was low, mainly because limonene accounted for more than $90 \%$ of the total composition, possibly masking numerous minor compounds.

The group composed of "Tosu", "Gou Tou", "Australian", "Fraser Seville", "Chinensis" and "Chinensis de semis" was more heterogeneous. "Gou Tou" and "Tosu" were characterized by a relatively lower limonene content 86.91 and $83.83 \%$ and high percentages of $\alpha$-pinene, sabinene, $\beta$-pinene and $p$-cymene. "Australian" and "Fraser Seville" presented a high limonene content of 94.06 and $95.81 \%$ respectively, which was similar to regular sour oranges and differed slightly based on their higher amount of neryl acetate $(0.29$ and $0.25 \%)$. Both cultivars were also characterized by a low content of linalool $(0.13$ and $0.08 \%$ ), and they differed from each other by their sabinene content ( 0.75 and $0.09 \%$, respectively). Concerning "Chinensis" and "Chinensis de semis", they differed from other cultivars by their low limonene content ( 56.49 and $64.75 \%$, respectively), higher content of $\gamma$-terpinene (8.82 and $18.01 \%$ ), higher content of $\alpha$-pinene (2.53 and $2.32 \%$ ), and higher ratio of $\beta$-pinene $/ \gamma$-terpinene, especially in "Chinensis".

\subsubsection{Peel Essential Oil Sensorial Analysis}

Cochran's Q-test $(p \leq 0.05)$ was significant only for seven of the twenty-nine sensory attributes studied (fat, musky, white blossom, cooked, lemon, pomelo and fresh), suggesting that all cultivars are statistically equivalent for all other sensory attributes. The expert panel detected sensory differences between samples but this diversity was relatively low because factorial correspondence analysis (FCA) explained only 55.39\% (Figure 7) of the observed variability across the first two axes. For instance, "Bitter sweet" and "N10 4XSG" stand out a slightly from the group by their 'musky' and 'pomelo' attributes, while "Apepu", "Algerie" and "Alibert" do so based on the 'white blossom' attribute.

Pearson's chi squared test performed on the contingency table of the seven attributes showed significant differences according to the Cochran Q-test and determine the existence of a statistical relationship between sensory attributes and cultivars with a $p$-value equal to 0.05 . Unfortunately, we were unable to establish correlation between sensory attributes and chemical composition. 


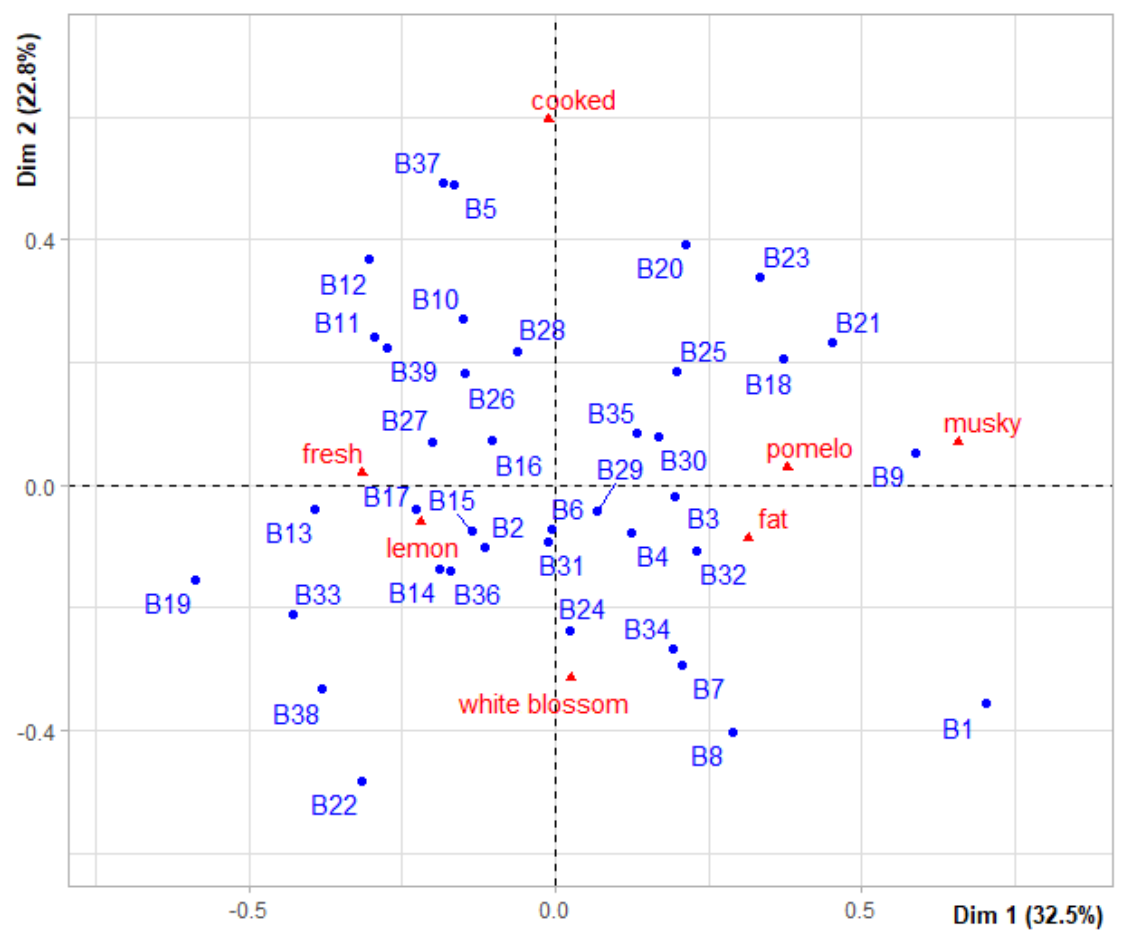

Figure 7. FCA plot representing the aromatic diversity of the thirty-nine PEO samples of regular sour orange cultivars based on the seven sensorial attributes (in red) that were significantly different in the varietal set. B1Bitter sweet", B2: "Luisi", B3: "A fleurs Ferando", B4: "Fleurs moyennes de Lucchi”, B5: “Grosses fleurs de Lucchi”, B6: “Curacao", B7: “Algerie”, B8: “Alibert”, B9: “N104XSG”, B10: “N114XSG", B11: “Bouquetier a fruit plat", B12: “CardosiA1”, B13: “Maroc SG", B14: “SEAB", B15: “Espagne”, B16: “Granito", B17: “Sweet”, B18: “Donnet", B19: “Alibert Hyb 12", B20: “Santucci”, B21: “Philippi", B22: “Apepu”, B23: “Bizzaria”, B24: “Menton”, B25: “Fleur grosse Carle”, B26: “Petit Pierre", B27: “Tunisie SG", B28: “Natsudaidai", B29: “Bouquetier de Nice”, B30: “Floride”, B31: "A fleur empereur", B32: “Corsigliese”, B33: “Tulear", B34: “Bouquetier a fleurs", B35: “Brazil sour", B36: "Variegated", B37: “Chinotto", B38: "Small leaves Chinotto", B39: “Wide leaves Chinotto".

\subsubsection{Leaf Essential Oil}

A total of fifty-three compounds were identified in the LEO of the forty-four cultivars (except "Bizzaria") accounting for 95.35 to $99.99 \%$ of the total composition (Table S7).

The LEO composition of the thirty-eight regular (except "Bizzaria") sour oranges was almost exclusively composed of terpenes (96.71-99.77\%) (Figure 8). Compared to PEO, LEO was richer and mainly composed of oxygenated compounds $(88.74-94.27 \%)$. This abundance of diverse compounds was more appropriate to perform diversity analysis and to discriminate cultivars.

The dominant compound was linalool, varying between 40.19 and $61.21 \%$, followed by linalyl acetate $(7.33-16.82 \%)$, $\alpha$-terpineol $(8.65-13.99 \%)$, geraniol $(4.87-8.02 \%)$ and geranyl acetate $(4.52-7.07 \%)$. A few compounds were present at approximately $1 \%$, such as $\beta$ pinene, myrcene, limonene, $(Z)-\beta$-ocimene, nerol and neryl acetate and the amounts of all remaining compounds were lower.

High proportions of $\beta$-pinene (37.27 and 37.09\%) characterized "Tosu" and "Gou Tou" respectively, whereas sabinene was the dominant compound of "Australian" and "Fraser Seville" (42.89 and 49.03\% respectively). "Chinensis" and "Chinensis de semis" were characterized by high proportions of limonene (38.64-36.57\%), neral (12.30-20.77\%) and geranial (16.56-28.45\%) and differed in $\beta$-pinene, with higher proportions for "Chinensis" $(13.38-0.08 \%)$. 


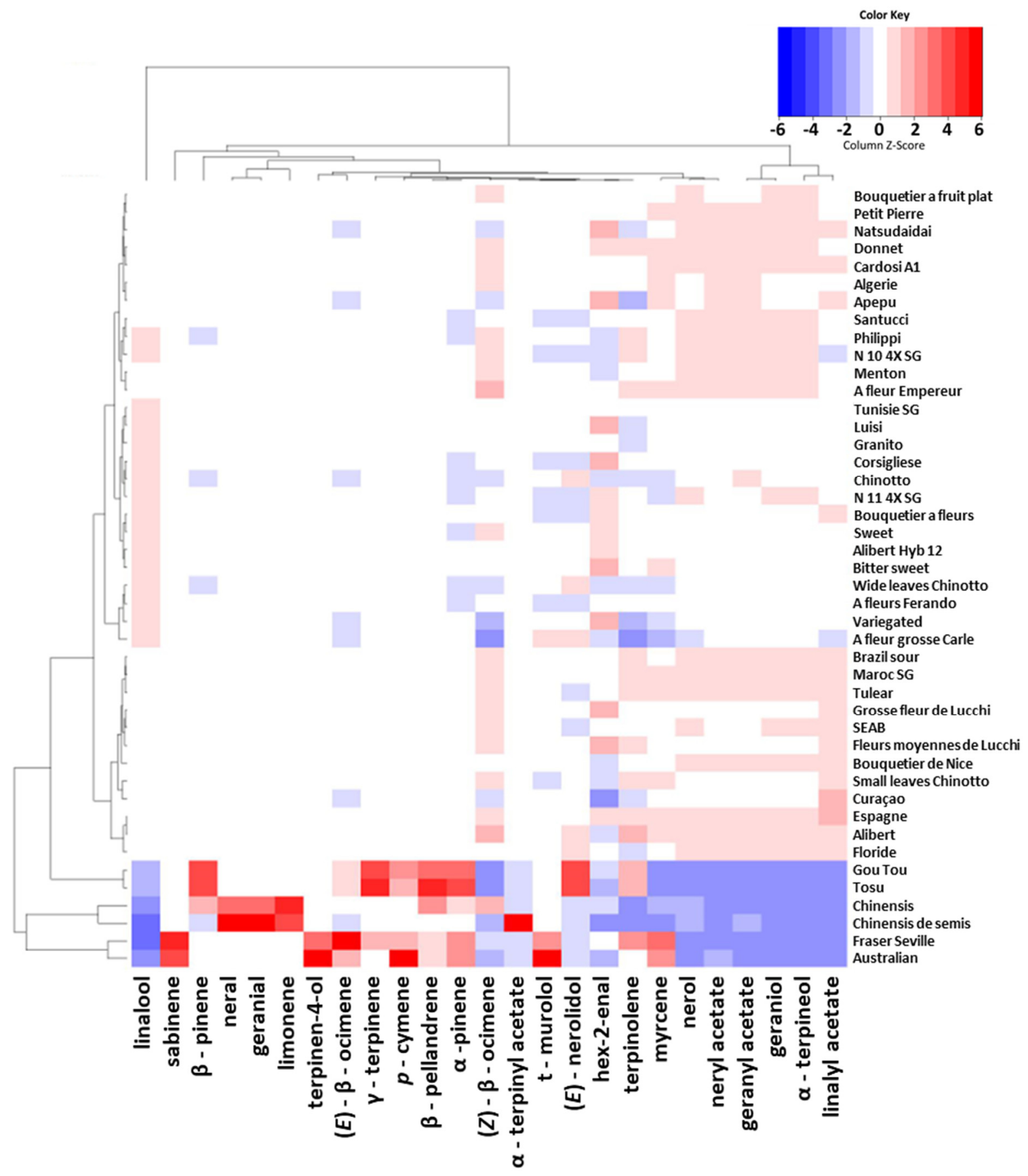

Figure 8. Heatmap based on the 25 main LEO compounds of the 44 sour oranges cultivars. The color of each square is scaled over the entire range of values for each compound. The color variation, from blue to red, indicates the position of the relative quantity of each aromatic compound compared to the average (white color) of all varieties (from low to high, respectively).

Taking into account the no negligible variations between varieties of regular sour oranges in terms of LEO compounds, such as linalyl acetate, $\alpha$-terpineol, geraniol and geranyl acetate, we reanalyzed the data with three LEO replicates (trees) from six cultivars exhibiting different proportions of these compounds (Table S8). The distinctness relationship between the eighteen samples established approximately three clusters or profiles: Blue for "Variegated", "Alibert Hyb12" and "Bouquetier a Fleurs"; red for "A fleur Ferando" and "Brazil sour" and yellow for "Tulear" (Figure 9). 


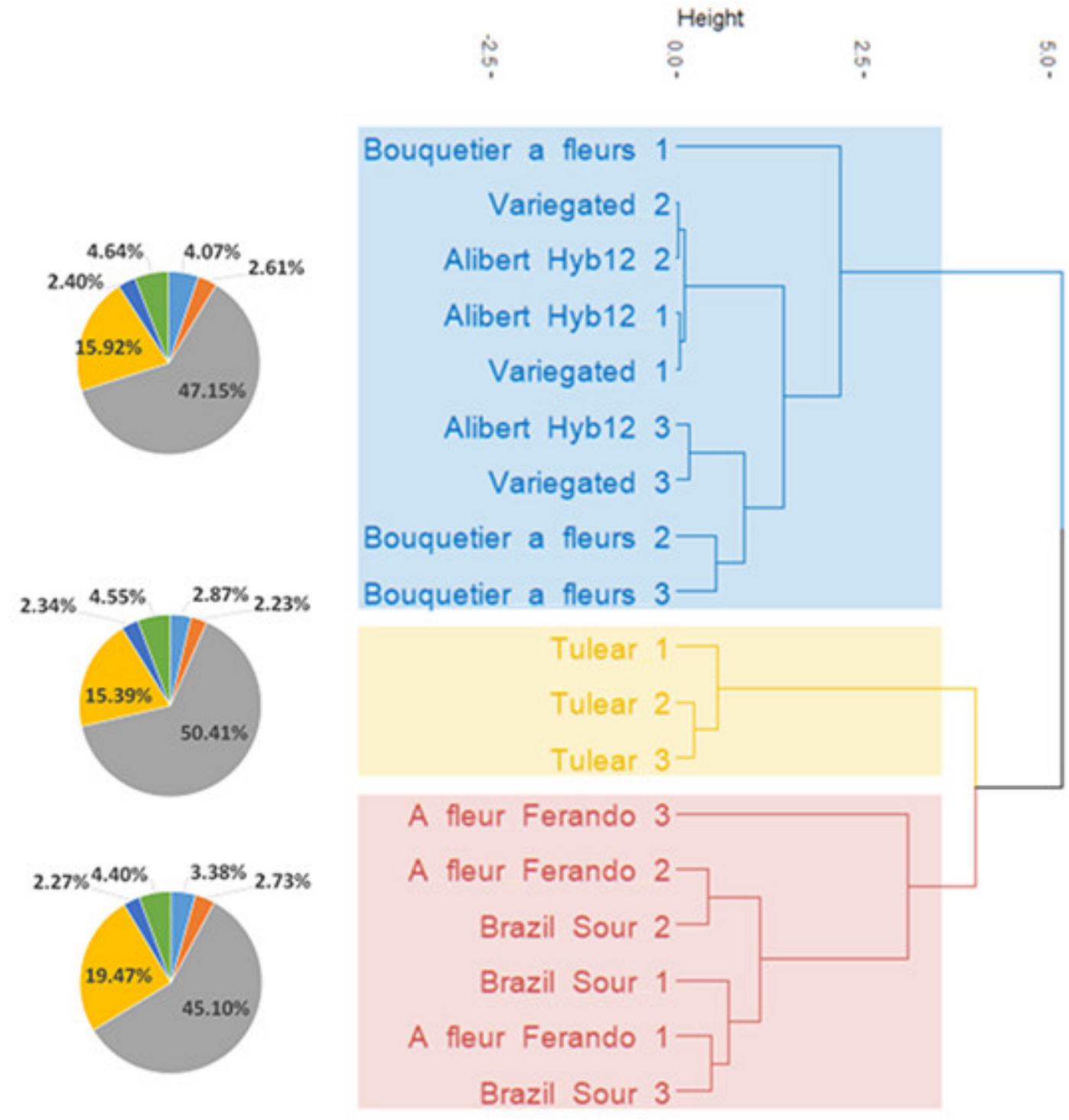

(a)

(b)

Figure 9. (a) Pie charts representing the mean proportion of the three clusters of the significantly $(p<0.05)$ different compounds between all cultivars. The colors correspond to the following compounds: grey, linalool; yellow, linalyl acetate; dark blue, neryl acetate; green, geranyl acetate; blue, $\beta$-pinene and orange, $(E)$ - $\beta$-ocimene. (b) Dendrogram based on the twenty-four main LEO compounds on six cultivars with three replicates.

It should be noted that the three replicates of each variety were most often grouped together, i.e., the intravarietal variation was smaller than the intervarietal variation. Significant differences between cultivars were identified for the following compounds: $\beta$ pinene, $(E)$ - $\beta$-ocimene, geranyl acetate, linalool, linalyl acetate and neryl acetate, suggesting three cluster specific chemotypes (Figure 9 and Table S8). The main differences between these three chemotypes are mainly based on the proportions of linalool, linalyl acetate and $\beta$-pinene.

\section{Discussion}

The microsatellites are known to present relatively high variability. However, it was recently demonstrated in citrus that the mutation of SSR markers is a rare event between two clonally propagated cultivars [26]. This conclusion concerning extremely low/absent genetic diversity is in accordance with previous work [20-26,49]. Studies using 
multilocus genotyping with dominant markers found higher diversity than studies using SSR markers [22,24]. Nevertheless, multilocus dominant markers suffer from a lack of repeatability and tend to overestimate the variability [50].

The relatively low diversity observed in the sour orange gene pool could be explained by the spread of a unique sour orange cultivar worldwide from China. In addition, other factors enabled the vegetative propagation of this unique clone, such as apomixes (by somatic embryogenesis) and grafting implying the conservation of a desired genotype.

Regular sour oranges have diversified by mutations or epigenetic modifications. These mechanisms have generated very important phenotypic variations in fruit traits. Fruit characteristics are directly submitted to disruptive selection for new fruit types by humans, which could better explain the greater diversity of fruit morphology than the composition of essential oils. We also observed important variability in the sweetness and acidity of the fruit pulp. This AC/TSS variability in the sour orange group seems to be as high as that observed by Luro et al. 2011 [19] in the mandarin group, where sexual crossing has been the main driver of genetic diversification [51]. The tetraploid cultivars presented a modified phenotype (highest TSS, PT, CCI) but a similar essential oil composition, in accordance with previous studies [52,53].

Concerning the aromatic characteristics, the PEO and LEO compositions of regular sour oranges were slightly influenced by the cultivar, consistent with the observed lack of genetic diversity and inconsistent with the high pomological diversity. This result agrees with those of previous studies [8,17]. However, the panel of sensory analysts detected variations in the fragrance of fruit EOs from different cultivars without allowing correlations to be established between aromatic compounds and odor profiles. Nonetheless, we only identified major compounds with a relative composition higher than $0.01 \%$ and may have missed odor active compounds at trace concentrations with lower odor thresholds [46]. For example, we were unable to detect compounds with a high sensory impact that were identified in previous studies such as (E,Z)-2,4-decadienal, cedrol, trans-dec-2-enal and $\beta$-elemol $[35,36]$. In addition, citrus flavor is known to be mainly influenced by minor compounds, so it may be valuable to perform GC-olfactometry of sour orange cultivars to distinguish them based on their odor profile and possibly identify compounds specific to certain cultivars [54]. Indeed, a point mutation has been observed to significantly alter some terpene synthase activities and could modify aromatic profiles [55,56].

The analysis of the LEO composition of a few cultivars, with biological repetitions (different trees) proved the existence of a variation, however small, of the profiles between cultivars.

If we consider that the appellation 'sour orange' only concerns the forms derived from the initial genotype resulting from a pummelo $x$ mandarin cross $(C . \times$ aurantium var. aurantium), then the diversity of SSR markers is none. On the other hand, if the term 'sour orange' includes morphotypes close to that of sour orange, then we consider that the sexual crossing also contributed to diversifying this group of citrus fruits. In this second option what would be the limits of belonging to the group of sour oranges? Can similar crosses (pummelo $\times$ mandarin) with different parental genotypes lead to hybrids that would be named 'sour orange'? Moreover, we have shown that there is not one regular sour orange morphotype but several such as "Chinotto" cultivars, which have very small fruits, resulting from mutations. "Gou Tou" and "Tosu" cultivars are morphologically, chemically and genetically identical and they probably came from the same cross a clonal selection. The complete and high heterozygosity of diagnostic SNPs in mandarins and pummelos respectively, suggest that these two cultivars also resulted from direct hybridization between a pummelo and a mandarin. Moreover, both cultivars have no alleles in common with regular sour oranges for three SSR markers, revealing a different origin than regular sour oranges. Considering these new elements, we propose to classify these two cultivars as $C$. $\times$ aurantium var. neoaurantium according to the new phylogenomic classification and species name from the classification of Tanaka [16]. 
The cultivars "Australian" (or "Smooth flat Seville") and "Fraser Seville" are both extremely similar on many aspects. Genetically they differ only by one marker. As previously discussed, those two cultivars probably originated from the same cross but from a different fecundation event. It was previously hypothesized that these two cultivars were not related to sour orange and that "Australian" originated from a sweet orange and grapefruit cross [22,24,25], however the SNP analysis again suggests a direct hybrid origin between a mandarin and a pummelo. Considering these elements, we propose classifying these two cultivars according to the new phylogenomic classification [16] as $C$. $\times$ aurantium var. superaurantium due to their large fruit size.

"Chinensis" and "Chinensis de semis" cultivars are the most morphologically, chemically and genetically distant from regular sour oranges. Based on molecular markers (SSRs and SNPs), their exact origin remains undetermined. Their PEO profile (limonene $/ \gamma-$ terpinene) and LEO profile limonene/neral/geranial confirm the genetic data and the tight relationship with $C$. medica [57]. The fruit and tree shapes of these cultivars present the same dwarf aspect as "Chinotto" suggesting "Chinotto" as a distant parent with additional C. medica properties (fruit shape, odor, color). These cultivars, being pummelo, mandarin and citron admixture, may be classified as $C . \times$ limon var. chinensis in the new phylogenomic classification.

\section{Conclusions}

Among sour oranges, three main genetic groups of $C . \times$ aurantium have been identified: a regular sour orange group represented by 39 varieties without intercultivar molecular diversity, a "Tosu" and "Gou Tou" pair, and "Australian" and "Fraser Seville" pair. The molecular marker analysis also revealed a strong contribution of C. medica to the "Chinensis" group discarding it from $C . \times$ aurantium and repositioning it with $C . \times$ limon. The morphological diversity among the regular sour oranges based only on mutation or epigenetics suggested the intervention of human selection on a variety of phenotypic traits. The main contributor to the chemical diversity was shared between the four mentioned groups. However, among the regular sour oranges we identified a significantly different LEO composition and significant different PEO aromatic profiles, suggesting the existence of chemical diversity, even in clonally propagated species. This result indicates that cultivar collections could be a valuable source of small variations in sour orange aroma, even for clonal selection. However, it seems that the mutation/selection process did not diversify the aromatic composition as much as it did the phenotype of the fruit and the chemical composition of its juice.

Supplementary Materials: The following are available online at https://www.mdpi.com/article/10 .3390 /agronomy11061084/s1. Table S1: List of accessions, Table S2: Check all that apply sensorial data, Table S3: Simple sequence repeat primers and data, Table S4: Single Nucleotide Polymorphism Kaspar primers and data, Table S5: Morphological data with statistics, Table S6: Peel essential oil data, Table S7: Leaf essential oil data, Table S8: Leaf essential oil triplicate data and statistics.

Author Contributions: P.O., F.T. and F.L. conceived and designed the experiment. V.F. drafted the manuscript. V.F. and G.C. realized the acquisition, analysis of genetic data. M.P. provided the technical support for the chromatography and mass spectrum analysis and V.F. acquired and analyzed the data. N.P. and C.Q. conceived and organized the sensorial analysis and V.F. analyzed the data. V.F., P.O., F.T. and F.L. wrote the manuscript. All authors have read and agreed to the published version of the manuscript.

Funding: This research was funded by the Association Nationale de la Recherche et de la Technologie (ANRT), grant number 2019/0084 for Vincent Ferrer's PhD. This work received financial support from the European Regional Development Fund under the framework PO FEDER-FSE Corse 20142020 number 247SAEUFEDER1A, project called Innov'Agrumes (ARR-18/517 CE, synergie number: CO 0009083).

Institutional Review Board Statement: Not applicable.

Informed Consent Statement: Not applicable. 
Acknowledgments: Thanks to Biological Resource Center (BRC) though the person of Olivier Pailly for the availability of biological material. Thanks for the technical support and the availability of Marc Gibernau, Elodie Marchi and Frederique Ollitrault. Thanks to Leslie Bernardini for her participation to chemical juice analysis. Special acknowledgments for the panelists of Rémy-Cointreau.

Conflicts of Interest: The authors declare no conflict of interest.

\section{References}

1. Wu, G.A.; Prochnik, S.; Jenkins, J.; Salse, J.; Hellsten, U.; Murat, F.; Perrier, X.; Ruiz, M.; Scalabrin, S.; Terol, J.; et al. Sequencing of diverse mandarin, pummelo and orange genomes reveals complex history of admixture during citrus domestication. Nat. Biotechnol. 2014, 32, 656-662. [CrossRef] [PubMed]

2. Wu, G.A.; Terol, J.; Ibanez, V.; López-García, A.; Pérez-Román, E.; Borredá, C.; Domingo, C.; Tadeo, F.; Carbonell-Caballero, J.; Alonso, R.; et al. Genomics of the origin and evolution of Citrus. Nat. Cell Biol. 2018, 554, 311-316. [CrossRef] [PubMed]

3. Deng, X.; Yang, X.; Yamamoto, M.; Biswas, M.K. The Genus Citrus; Talon, M., Caruso, M., Gmitter, J.F.G., Eds.; Elsevier WP: Duxford, UK, 2020; pp. 33-56, ISBN 978-0-12-812217-4.

4. Castle, W.S. A Career Perspective on Citrus Rootstocks, Their Development, and Commercialization. Hort. Sci. 2010, 45, 11-15. [CrossRef]

5. Moreno, P.; Ambrós, S.; Albiach-Martí, M.R.; Guerri, J.; Peña, L. Citrus tristeza virus: A pathogen that changed the course of the citrus industry. Mol. Plant Pathol. 2008, 9, 251-268. [CrossRef] [PubMed]

6. Gómez-Muñoz, N.; Velázquez, K.; Vives, M.C.; Ruiz-Ruiz, S.; Pina, J.A.; Flores, R.; Moreno, P.; Guerri, J. The resistance of sour orange to Citrus tristeza virus is mediated by both the salicylic acid and RNA silencing defence pathways. Mol. Plant Pathol. 2016, 18, 1253-1266. [CrossRef]

7. Anwar, S.; Ahmed, N.; Speciale, A.; Cimino, F.; Saija, A. Bitter Orange (Citrus aurantium L.) Oils. In Essential Oils in Food Preservation, Flavor and Safety, 1st ed.; Preedy, V.R., Ed.; Academic Press: Cambridge, MA, USA; Elsevier BV: Amsterdam, The Netherlands, 2016; pp. 259-268.

8. Lota, M.-L.; Serra, D.D.R.; Jacquemond, C.; Casanova, J. Chemical variability of peel and leaf essential oils of sour orange. Flavour Fragr. J. 2001, 16, 89-96. [CrossRef]

9. Peyron, L. Citrus: The Genus Citrus; Dugo, G., Di Giacomo, A., Eds.; Taylor \& Francis, CRC Press: London, UK, 2002; Volume 26, pp. 148-152, ISBN 978-0-415-28491-2.

10. Dugo, G.; Bonaccorsi, I.L.; Sciarrone, D.; Costa, R.; Dugo, P.; Mondello, L.; Santi, L.; Fakhry, H.A. Characterization of Oils from the Fruits, Leaves and Flowers of the Bitter Orange Tree. J. Essent. Oil Res. 2011, 23, 45-59. [CrossRef]

11. Swingle, W.T.; Reece, P.C.; Reuther, W.; Webber, H.J.; Batchelor, L.D. The Citrus Industry; University of Calofornia Press: Berkeley, CA, USA, 1967; pp. 190-430.

12. Tanaka, T. Fundamental Discussion of Citrus Classification; Studia Citrologica: Osaka, Japan, 1977; Volume 14, pp. 1-6.

13. Mabberley, D. A classification for edible Citrus (Rutaceae). Telopea 1997, 167-172. [CrossRef]

14. Wooldridge, T.J.S. Cross-Compatibility, Graft-Compatibility, and Phylogenetic Relationships in the Auranti-oideae: New Data from the Balsamocitrinae. Ph.D. Thesis, University of Calfornia, Riverside, CA, USA, 2016.

15. Bernet, G.P.; Asíns, M.J. Identification and genomic distribution of gypsy like retrotransposons in Citrus and Poncirus. Theor. Appl. Genet. 2003, 108, 121-130. [CrossRef]

16. Ollitrault, P.; Curk, F.; Krueger, R. Citrus taxonomy. In The Genus Citrus; Talon, M., Caruso, M., Gmitter, J.F.G., Eds.; Elsevier WP: Duxford, UK, 2020; pp. 57-81, ISBN 978-0-12-812217-4.

17. Gogorcena, Y.; Ortiz, J.M. Characterisation of sour orange (Citrus aurantium) cultivars. J. Sci. Food Agric. 1989, 48, 275-284. [CrossRef]

18. Gogorcena, Y.; Ortiz, J. Use of multivariate analysis in the taxonomy of Citrus aurantium L. and relatives. Sci. Hortic. 1993, 53, 301-310. [CrossRef]

19. Luro, F.; Gatto, J.; Costantino, G.; Pailly, O. Analysis of genetic diversity in Citrus. Plant Genet. Resour. 2011, 9, 218-221. [CrossRef]

20. Luro, F.; Rist, D.; Ollitrault, P. Evaluation of genetic relationships in citrus genus by means of sequence tagged microsatellites. Acta Hortic. 2001, 237-242. [CrossRef]

21. Barkley, N.A.; Roose, M.L.; Krueger, R.R.; Federici, C.T. Assessing genetic diversity and population structure in a citrus germplasm collection utilizing simple sequence repeat markers (SSRs). Theor. Appl. Genet. 2006, 112, 1519-1531. [CrossRef]

22. Polat, I.; Kaçar, Y.; Yesiloglu, T.; Uzun, A.; Tuzcu, O.; Gulsen, O.; Incesu, M.; Kafa, G.; Turgutoglu, E.; Anil, S. Molecular characterization of sour orange (Citrus aurantium) accessions and their relatives using SSR and SRAP markers. Genet. Mol. Res. 2012, 11, 3267-3276. [CrossRef]

23. Luro, F.; Viglietti, G.; Marchi, E.; Costantino, G.; Scarpa, G.M.; Tomi, F.; Paoli, M.; Curk, F.; Ollitrault, P. Genetic, morphological and chemical investigations reveal the genetic origin of Pompia (C. medica tuberosa Risso \& Poiteau)—An old endemic Sardinian citrus fruit. Phytochemistry 2019, 168, 112083. [CrossRef]

24. Siragusa, M.; De Pasquale, F.; Abbate, L.; Tusa, N. Identification of Sour Orange Accessions and Evaluation of Their Genetic Variability by Molecular Marker Analyses. HortScience 2006, 41, 84-89. [CrossRef] 
25. Bernet, G.P.; Gorris, M.T.; Carbonell, E.A.; Cambra, M.; Asins, M.J. Citrus tristeza virusresistance in a core collection of sour orange based on a diversity study of three germplasm collections using QTL-linked markers. Plant Breed. 2008, 127, 398-406. [CrossRef]

26. Shimizu, T.; Kitajima, A.; Nonaka, K.; Yoshioka, T.; Ohta, S.; Goto, S.; Toyoda, A.; Fujiyama, A.; Mochizuki, T.; Nagasaki, H.; et al. Hybrid Origins of Citrus Varieties Inferred from DNA Marker Analysis of Nuclear and Organelle Genomes. PLoS ONE 2016, 11, e0166969. [CrossRef]

27. Maekawa, K.; Kodama, M.; Kushii, M.; Mitamura, M. Essential Oils of Some Orange Peels. Agric. Biol. Chem. 1967, 31, 373-377. [CrossRef]

28. Shaw, P.E. Review of quantitative analyses of citrus essential oils. J. Agric. Food Chem. 1979, 27, 246-257. [CrossRef]

29. Dugo, G.; Cotroneo, A.; Bonaccorsi, I.; Trozzi, A. Citrus Oils: Composition, Advanced Analytical Techniques, Contaminants, and Biological Activity, 1st ed.; Dugo, G., Modello, L., Eds.; CRC Press: Boca Raton, FL, USA, 2010; pp. 10-20, ISBN 978-1-4398-0029-4.

30. González-Mas, M.C.; Rambla, J.L.; López-Gresa, M.P.; Blázquez, M.A.; Granell, A. Volatile Compounds in Citrus Essential Oils: A Comprehensive Review. Front. Plant Sci. 2019, 10, 12. [CrossRef]

31. Gaff, M.; Esteban-Decloux, M.; Giampaoli, P. Bitter orange peel essential oil: A review of the different factors and chemical reactions influencing its composition. Flavour Fragr. J. 2020, 35, 247-269. [CrossRef]

32. Boussaada, O.; Skoula, M.; Kokkalou, E.; Chemli, R. Chemical Variability of Flowers, Leaves, and Peels Oils of Four Sour Orange Provenances. J. Essent. Oil Bear. Plants 2007, 10, 453-464. [CrossRef]

33. Boussaada, O.; Chemli, R. Seasonal Variation of Essential Oil Composition of Citrus Aurantium, L. var. amara. J. Essent. Oil Bear. Plants 2007, 10, 109-120. [CrossRef]

34. Ellouze, I.; Abderrabba, M.; Sabaou, N.; Mathieu, F.; Lebrihi, A.; Bouajila, J. Season's Variation Impact onCitrus aurantiumLeaves Essential Oil: Chemical Composition and Biological Activities. J. Food Sci. 2012, 77, 173-180. [CrossRef]

35. Song, H.S.; Sawamura, M.; Ito, T.; Ido, A.; Ukeda, H. Quantitative determination and characteristic flavour of daidai (Citrus aurantium L. var.cyathifera Y. Tanaka) peel oil. Flavour Fragr. J. 2000, 15, 323-328. [CrossRef]

36. Deterre, S.; Rega, B.; Delarue, J.; Decloux, M.; Lebrun, M.; Giampaoli, P. Identification of key aroma compounds from bitter orange (Citrus aurantium L.) products: Essential oil and macerate-distillate extract. Flavour Fragr. J. 2011, 27, 77-88. [CrossRef]

37. Luro, F.; Bloquel, E.; Tomu, B.; Costantino, G.; Tur, I.; Riolacci, S.; Varamo, F.; Ollitrault, P.; Froelicher, Y.; Curk, F.; et al. The INRACIRAD Citrus Germplasm Collection of San Giuliano, Corsica; Publications du Centre Jean Bérard: Naples, Italy, 2017 ; pp. 243-261. [CrossRef]

38. Jimenez-Cuesta, M.; Cuquerella, J.; Martinez-Javaga, J.M. Determination of a color index for citrus fruit de-greening. In Proceedings of the International Society of Citriculture/International Citrus Congres, Tokyo, Japan, 9-12 November 1982.

39. Wickham, H. ggplot2: Elegant Graphics for Data Analysis, 2nd ed.; Springer International Publishing: New York, NY, USA, 2016; pp. 3-253, ISBN 978-3-319-24275-0.

40. Gomez, K.A.; Gomez, A.A. Statistical Procedures for Agricultural Research, 2nd ed.; John Wiley \& Sons: New York, NY, USA, 1984; pp. 3-700, ISBN 978-0-471-87092-0.

41. Thioulouse, J.; Dray, S.; Dufour, A.; Siberchicot, A.; Jombart, T.; Pavoine, S. Multivariate Analysis of Ecological Data with ade4, 1st ed.; Springer: New York, NY, USA, 2018; pp. 3-329, ISBN 978-1-4939-8850-1.

42. Lê, S.; Josse, J.; Husson, F. FactoMineR: AnRPackage for Multivariate Analysis. J. Stat. Softw. 2008, 25, 1-18. [CrossRef]

43. Kassambara, A.; Mundt, F. Factoextra: Extract and Visualize the Results of Multivariate Data Analyses. R Package Version 1.0.7. 2020. Available online: https:/ /CRAN.R-project.org/package=factoextra (accessed on 25 January 2021).

44. Warnes, G.R.; Bolker, B.; Bonebakker, L.; Gentleman, R.; Huber, W.; Liaw, A.; Lumley, T.; Maechler, M.; Magnusson, A.; Moeller, S.; et al. Gplots: Various R Programming Tools for Plotting Data. Available online: https://CRAN.R-project.org/ package $=$ gplots (accessed on 25 January 2021).

45. Hervé, M. RVAideMemoire: Testing and Plotting Procedures for Biostatistics. R Package Version 0.9-79. 2020. Available online: https: / /CRAN.R-project.org/package=RVAideMemoire (accessed on 25 January 2021).

46. Luro, F.L.; Costantino, G.; Terol, J.; Argout, X.; Allario, T.; Wincker, P.; Talon, M.; Ollitrault, P.; Morillon, R. Transferability of the EST-SSRs developed on Nules clementine (Citrus clementina Hort ex Tan) to other Citrus species and their effectiveness for genetic mapping. BMC Genom. 2008, 9, 287. [CrossRef]

47. Ligges, U.; Mächler, M. Scatterplot3d-An R Package for Visualizing Multivariate Data. J. Stat. Softw. 2003, 8, 1-20. [CrossRef]

48. Curk, F.; Ancillo, G.; Ollitrault, F.; Perrier, X.; Jacquemoud-Collet, J.-P.; Garcia-Lor, A.; Navarro, L.; Ollitrault, P. Nuclear SpeciesDiagnostic SNP Markers Mined from 454 Amplicon Sequencing Reveal Admixture Genomic Structure of Modern Citrus Varieties. PLoS ONE 2015, 10, e0125628. [CrossRef]

49. Lombardo, G.; Schicchi, R.; Marino, P.; Palla, F. Genetic analysis ofCitrus aurantiumL. (Rutaceae) cultivars by ISSR molecular markers. Plant Biosyst. Int. J. Deal. Asp. Plant Biol. 2011, 146, 19-26. [CrossRef]

50. Bretó, M.; Ruiz, C.; Pina, J.; Asíns, M. The Diversification of Citrus clementina Hort. ex Tan., a Vegetatively Propagated Crop Species. Mol. Phylogenet. Evol. 2001, 21, 285-293. [CrossRef]

51. Garcia-Lor, A.; Luro, F.; Ollitrault, P.; Navarro, L. Genetic diversity and population structure analysis of mandarin germplasm by nuclear, chloroplastic and mitochondrial markers. Tree Genet. Genomes 2015, 11, 1-15. [CrossRef]

52. Barrett, H.C.; Hutchison, D.J. Spontaneous Tetraploidy in Apomietie Seedlings of Citrus. Econ. Bot. 1978, 32, 27-45. [CrossRef] 
53. Cameron, J.W.; Scora, R.W. A Comparison of rind oil components of diploid and tetraploid citrus by gas-liquid-chromatography. Taxon 1968, 17, 128-135. [CrossRef]

54. Rouseff, R.L.; Perez-Cacho, P.R.; Jabalpurwala, F. Historical Review of Citrus Flavor Research during the Past 100 Years. J. Agric. Food Chem. 2009, 57, 8115-8124. [CrossRef] [PubMed]

55. Kohzaki, K.; Gomi, K.; Yamasaki-Kokudo, Y.; Ozawa, R.; Takabayashi, J.; Akimitsu, K. Characterization of a sabinene synthase gene from rough lemon (Citrus jambhiri). J. Plant Physiol. 2009, 166, 1700-1704. [CrossRef] [PubMed]

56. Alquézar, B.; Rodríguez, A.; De La Peña, M.; Peña, L. Genomic Analysis of Terpene Synthase Family and Functional Characterization of Seven Sesquiterpene Synthases from Citrus sinensis. Front. Plant Sci. 2017, 8, 1481. [CrossRef]

57. Lota, M.-L.; de Rocca Serra, D.; Tomi, F.; Bessiere, J.-M.; Casanova, J. Chemical Composition of Peel and Leaf Essential Oils of Citrus Medica, L. and C. Limonimedica Lush. Flavour Fragr. J. 1999, 14, 161-166. [CrossRef] 